\title{
Inclusive wealth in the twenty-first century: a summary and further discussion of Inclusive Wealth Report 2018
}

\author{
Rintaro Yamaguchi ${ }^{1}$ (D) Moinul Islam ${ }^{2,3}$ (D) Shunsuke Managi ${ }^{2,3}$
}

Received: 18 September 2018 / Accepted: 25 April 2019 / Published online: 7 May 2019

(c) The Author(s) 2019

\begin{abstract}
It is increasingly common to judge the sustainable development of nations by nondeclining social well-being. Determinants of social well-being have been measured and used for sustainability analysis. In particular, inclusive wealth per capita, which comprises produced, human, and natural capital, was reported in the Inclusive Wealth Report in 2012 and 2014. Here, we report the updates of the third edition of the report, which covers 140 countries from 1990 to 2014. In per capita terms, only 60\% out of 140 countries show non-declining wealth for the past quarter century. Most countries, both developed and developing, fall into the group of running down natural capital and increasing produced and, to a lesser extent, human capital. We also include fishery stock as part of natural capital, and we find that only a few countries have increased their fishery capital in the studied period. Inclusive wealth has typically grown much less than GDP per capita and does not resemble change in other development indices. Globally aggregated produced and human capital per capita increased $94 \%$ and $28 \%$, respectively, while natural capital per capita declined by $34 \%$. In 2014, produced, human, and natural capital account for $24 \%, 64 \%$, and $11 \%$, respectively, which is similar to the recent findings by the World Bank. In addition, inclusive wealth is approximately 12 times GDP on average, much higher than conventional wealthincome ratios globally, and is at least at par with those ratios in high-income countries under financialization.
\end{abstract}

Keywords Sustainable development · Inclusive wealth · Natural capital · Produced capital · Human capital

JEL Classification Q01 · E01 · I15

Electronic supplementary material The online version of this article (https://doi.org/10.1007/s12076019-00229-x) contains supplementary material, which is available to authorized users. 


\section{Introduction}

Among a myriad of alternatives to gross domestic product (GDP) is a determinantbased approach that measures social well-being in terms of capital assets (Dasgupta 2001). Around the turn of the century, it was formally shown that the sign of the change in capital assets, weighted by shadow prices, is equivalent to the direction of intergenerational (i.e., social) well-being in both optimal and imperfect economies (Hamilton and Clemens 1999; Dasgupta and Mäler 2000). Development is deemed sustainable at a given time $t$, in the sense of Bruntland Commission (World Commission on Environment and Development 1987), if and only if the aggregate change in the value of produced, human, and natural capital assets increases at $t$ based on their shadow prices (i.e., their contribution to social well-being). Carbon damage, oil capital gains, and total factor productivity (TFP) are also adjusted to account for wellbeing changes not brought about via these three types of capital assets. TFP signifies the overall efficiency of institutions and the knowledge with which the three types of capital assets are used.

Applications of this determinant-based approach to sustainability measurement now abound at varied scales and levels of rigor (Arrow et al. 2012; Greasley et al. 2014; World Bank 2011; Yamaguchi et al. 2016). Among them, the Inclusive Wealth Report (IWR) was inaugurated in accordance with the United Nations Conference on Sustainable Development, 'Rio + 20', in 2012. IWR 2012 measured the produced, human, and natural capital of 20 large economies (UNU-IHDP and UNEP 2012). Their follow-up, IWR 2014, covered these three types of capital for 140 countries, 1990-2014 (UNU-IHDP and UNEP 2014). Now, IWR 2018 (Managi and Kumar 2018) has been published, and it is summarized in the current paper. Moreover, we propose some corrections and further discuss global wealth, the wealth-income ratio, and comparisons with the World Bank's measurement of wealth.

\section{Methods}

We outline our underlying framework, which is premised on the body of work in the literature on green accounting, especially under imperfect economies (Arrow et al. 2012). We are interested in whether development is sustainable in the sense that intertemporal well-being at $t$,

$$
V(t)=\int_{t}^{\infty} U\left(C_{\tau}\right) e^{-\delta(\tau-t)} d \tau,
$$

is not declining. This expression is merely a discounted sum of instantaneous wellbeing. Note that the economy may be maximizing $V(t)$, which is not equivalent to non-declining $V(t)$. A central assumption is that this intertemporal well-being is a function of capital assets in the economy. Thus, denoting produced, human, and natural capital as $K, H$, and $N$, we have the following equivalence between inclusive wealth (IW) and well-being: 


$$
W(K(t), H(t), N(t), t)=V(t)=\int_{t}^{\infty} U(C(\tau)) e^{-\delta(\tau-t)} d \tau,
$$

where $W$ is IW. Then, sustainable development is equivalent to non-declining IW. Formally, we ensure the sign of the temporal change of IW,

$$
\frac{d W(K, H, N, t)}{d t}=p_{K} \frac{d K}{d t}+p_{H} \frac{d H}{d t}+p_{N} \frac{d N}{d t}+\frac{\partial V}{\partial t},
$$

where $p_{K}, p_{H}$ and $p_{K}$ are the marginal shadow prices of produced, human, and natural capital, respectively. Note that aside from the three-capital channel, we have a direct channel through which only the passing of time directly affects well-being. The shadow prices are essentially marginal contributions to the intertemporal well-being of an additional unit of capital in question. They are formally defined by

$$
p_{K} \equiv \frac{\partial V}{\partial K}, p_{H} \equiv \frac{\partial V}{\partial H}, p_{N} \equiv \frac{\partial V}{\partial N},
$$

given a forecast of how produced, human, and natural capital, as well as other flow variables, evolve in the future in the economy in question. ${ }^{1}$ In practice, shadow prices act as a weight factor attached to each type of capital, resulting in the measure of wealth, or the inclusive wealth index (IWI):

$$
I W I=p_{K} K+p_{H} H+p_{N} N
$$

Note that IWI is a linear index, so a change in $W$ and a change in IWI are equivalent only over a short period of time, as shadow prices are defined as the marginal changes when there is a hypothetical, small perturbation in capital assets. Accordingly, over an interval of time, capital gains accrued on capital assets should be deducted from the change in $W$ to obtain the change in social well-being (Arrow et al. 2012). ${ }^{2}$ In our accounting, barring oil capital gains, which we elaborate on later, we omit the change in the shadow prices, since it suffices to use fixed, average shadow prices within a relatively short period of time. It also makes practical sense in our report since fixing shadow prices will enable us to focus on the quantity changes in capital assets and remove price volatility. Moreover, the period-average shadow price would not mislead if the underlying shadow price function were linear (Fenichel et al. 2016b).

\footnotetext{
1 In practical accounting, for human and renewable natural capital, the net present values of wages or rental prices are used to calculate shadow prices so that they are forward-looking. In contrast, the shadow prices of produced capital and non-renewable natural capital are backward- and present-looking, respectively (Yamaguchi and Managi 2019). Given a lack of sound projections of those prices, wages and rental prices are assumed to be constant. Lange et al. (2018) assume that the wage rate grows implicitly at $2.5 \%$, reflecting future increases in efficiency.

2 When reckoning the real $W$, it is obvious that, for example, the last drop of oil should have a different marginal value than a regular drop when oil is not scarce.
} 


\section{Results}

Have nations been maintaining their wealth for the past quarter century? Our results suggest that $95 \%$ of nations have enjoyed positive growth rates in IW during this period. However, if we change the measure from total to per capita, only $60 \%$ of nations under study present positive growth in IW. Notably, almost all European and North American countries have experienced increasing wealth in both absolute and per capita terms. In contrast, countries with negative growth in IW per capita are typically in Africa, Asia, or Latin America and the Caribbean (Fig. 1).

Figure 2 plots the average annual growth rate of wealth and natural capital per capita into four quadrants (Q1-Q4). Countries achieving both strong and weak forms of sustainability are few and far between (Q1). The concept of weak sustainability assumes that manufactured and natural capital are close substitutes. However, the concept of strong sustainability denies the assumption of this substitutability, at least for some critical elements of natural capital. Most countries, both developed and developing, fall into the group of running down natural capital and increasing other forms of capital (Q4). To our concern, there are still many countries that have degraded both natural capital and IW, particularly in Africa and Asia and the Pacific (Q3). It is highly likely that they are not successful in managing natural resources and transforming them into wealth. We briefly note that part of this rundown is traceable to international trade of natural resources, which is recorded as natural capital depletion of exporting countries. In contrast, Atkinson et al. (2012) in IWR 2012 account for virtual sustainability of resource importing nations by constructing consumption-based genuine savings.

If we take a closer look at the breakdown of the contributions of each capital asset, the composition varies even within high-IW-growth countries. For example, oil-rich gulf nations have converted massive natural capital into other types of capital, especially human capital. Other nations have been on a sustainable path primarily

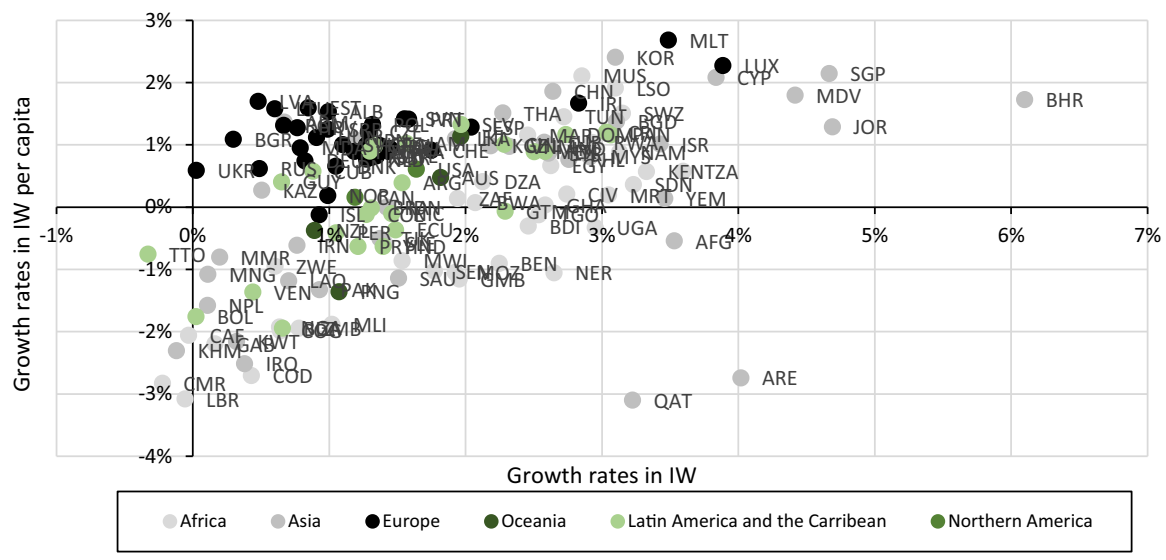

Fig. 1 Growth rates in inclusive wealth and inclusive wealth per capita, 1990-2014. Source: IWR 2018, Figure 1.20 (p. 31) 


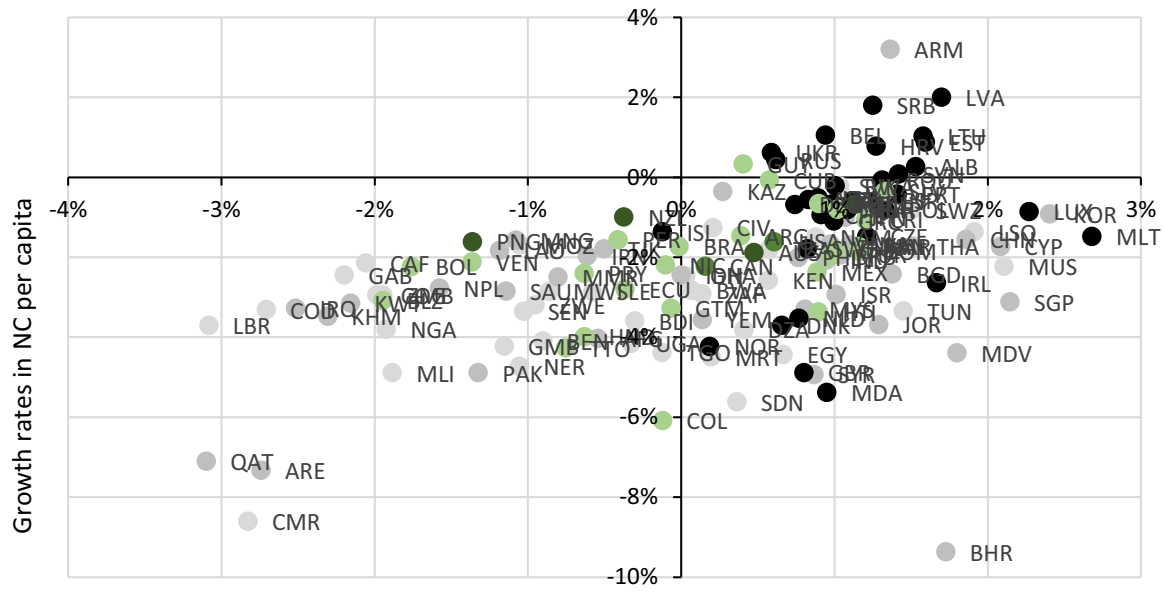

Growth rates in IW per capita

Africa

Asia

Europe

Oceania

Latin America and the Carribean

Northern America

Fig. 2 Growth rates in inclusive wealth (IW) per capita and natural capital (NC) per capita, 1990-2014

because they grow their produced capital, with very little rundown of their natural resources, or because they are poorly endowed with these resources in the first place.

We also include fishery resources as part of natural capital. Our calculation shows that around the world, the value of fishery stock has decreased from $\$ 2325$ billion to $\$ 1713$ billion. It is sobering to observe that among countries affiliated with a large amount of fishery stock, only Canada and Spain increased their level in the period from 1990 to 2014. However, the relative magnitude of fishery stock within natural capital is not large.

Has the world been preserving its wealth globally? Natural scientists have warned about global sustainability in terms of planetary boundaries (Steffen et al. 2015). Since the marginal utility of consumption is different across countries, aggregating national figures to reach global IW is not without problems. ${ }^{3}$ That said, the most straightforward approach is simply to add up total change in capital assets in dollars. Produced and human capital per capita increased $94 \%$ and $28 \%$, respectively, while natural capital per capita declined by 34\% from 1992 to 2014, as shown in Fig. 3a. ${ }^{4}$ Put together, wealth per capita has been slightly positive, especially over the last decade, as shown in Fig. 3b. In contrast, GDP per capita growth has been mostly linearly positive, except for an enormous drop in this trend in 2009 due to the Great Recession.

Only the comparison of wealth across time or space (nations), rather than the absolute value of wealth per se, can have welfare significance (Arrow et al. 2012). Acknowledging this, it is interesting to show wealth composition across the whole world. Figure $3 \mathrm{c}$ indicates that on average, human capital is responsible for more than

\footnotetext{
3 Another promising aggregation would be to use purchasing power parity (PPP) dollars, as an additional dollar gives a different well-being implication for different countries (Lange et al. 2018).

4 The years 1990 and 1991 are skipped here to avoid missing data in some former Soviet republics.
} 


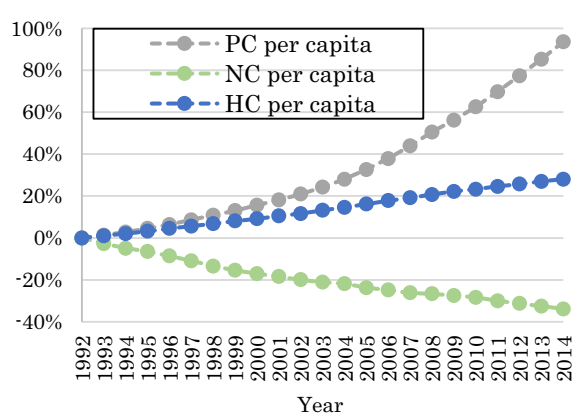

(a)

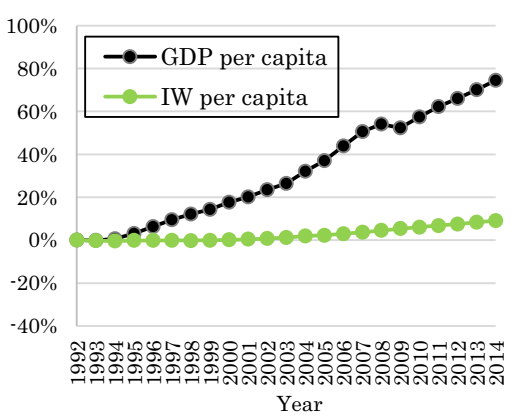

(b)

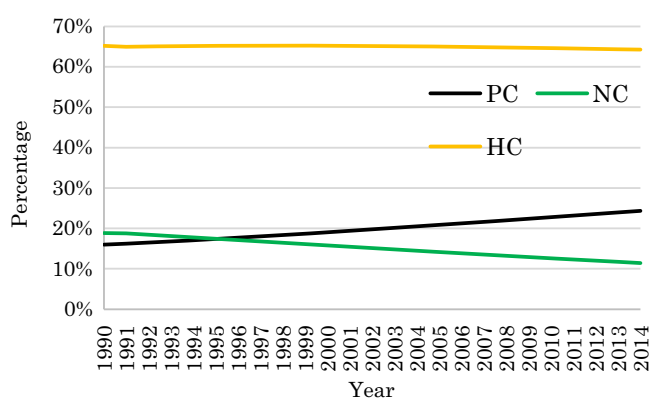

(c)

Note: PC, NC and HC stand for produced, natural and human capital, respectively.

Fig. 3 Growth rates of inclusive wealth per capita and its components (a, b) and global aggregate wealth composition change (c). Note: PC, NC and HC stand for produced, natural and human capital, respectively. Source: IWR 2018, Figure 1.22 (p. 33) and Figure 1.24b (p. 36)

half of IW. Natural capital has been substituted almost equally by produced and human capital.

However, if we turn back to cross-country data in Fig. 4, it seems to be human capital that substitutes natural capital, although cross sectional data can show only the relationship and not causality. A crude approximation suggests that if one starts from the state of natural capital being $100 \%$ of wealth, a $20 \%$ decrease in natural capital would translate into a $15 \%$ increase in human capital.

There are at least three exogenous factors that affect social well-being that we have not touched upon in the three capital channels: carbon damage, oil capital gains, and TFP. The three terms are added to the growth rate in IW per capita to arrive at IW per capita adjusted. As it turns out, carbon damage, calculated according to its effect on the economy of the nation that actually suffers the damages as a share of IW, affects small countries more because their IW tends not to be sufficiently large enough to absorb such exogenous shocks. Oil capital gains boost total wealth by an exogenous increase in the price of natural resources. Over the last quarter century, dozens of oil-exporting countries have experienced oil capital gains, while importing countries with negative oil capital gains comprise the majority (113 of 140 countries). 


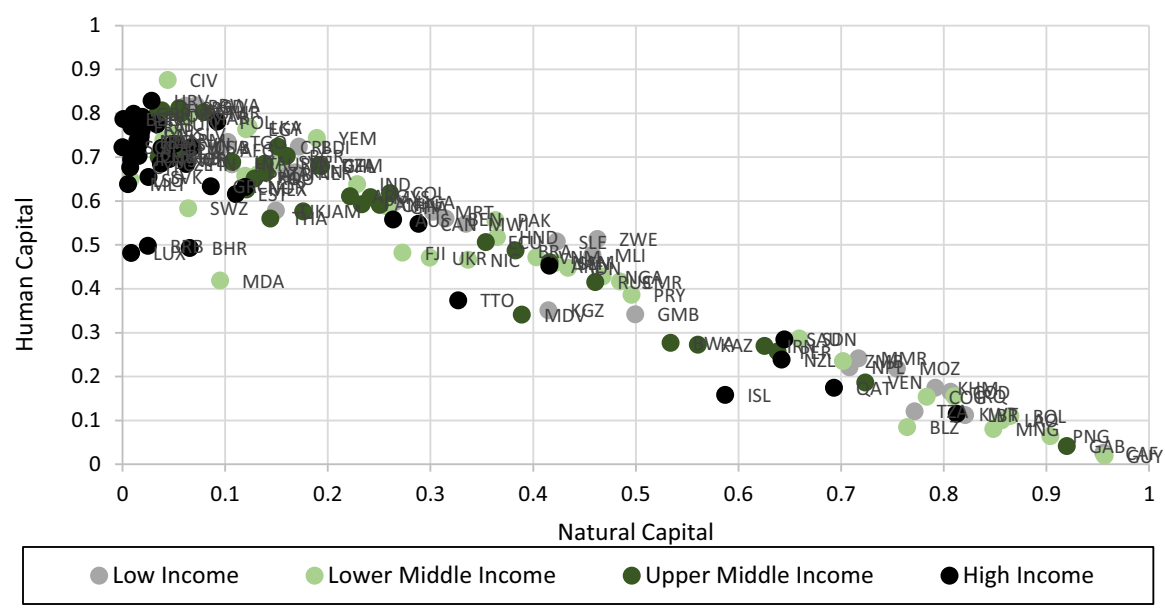

Fig. 4 Percentage shares of human capital and natural capital in total wealth, average 1990-2014. Source: IWR 2018, Figure 1.24c (p. 36)

Finally, the economy can also enjoy improved social well-being in the presence of an increase in TFP, representing technological progress, improvements in knowledge and institutions. ${ }^{5}$ Put together, $58 \%$ of the studied countries have experienced an increase in IW per capita adjusted, including these three adjustments.

How does the IWI make a difference? It proves useful to compare our results with other indicators of economic development. GDP per capita is the most popular index to date for monitoring the progress of nations, but it has been criticized for sending an incorrect message regarding the sustainability of social well-being (Stiglitz et al. 2009). In actuality, Fig. 5 shows that while most countries have experienced growth in GDP per capita, many of them have experienced decreased IW per capita. Moreover, Quadrant 2 tends to include low- and lower-middle-income countries as well as resource-rich economies.

The Human Development Index (HDI) is a composite index of human capital (health and education) and income levels (GDP per capita). We find no apparent relationship between IWI and HDI (Figure S1a). For lower middle-income countries, their correlation is even slightly negative.

One of the indexes closest to ours is the World Bank's genuine savings (GS), formally known as adjusted net savings, which also keeps track of savings in produced, human, and natural capital. The growth in IWI and GS are equivalent in theory but different in methodology. Among other differences, human capital is measured as outputs (i.e., return on education) in IWI instead of inputs (i.e., education expenditure) in GS. In terms of natural capital, the increase in agricultural land, discoveries in nonrenewable natural capital, and capital gains are not recorded in GS because GS is more in line with national accounting (Lange et al. 2018). Thus, it was expected that IWI and GS do not correlate strongly, which turned out to be true (Figure S1c). In summary,

\footnotetext{
5 We realize that some previous studies stress the role of technological progress in well-being change in theory (Weitzman 1997) and in empirics (Greasley et al. 2014). Our treatment here, in line with Arrow et al.'s (2012), may thus be an underestimate on the conservative side.
} 


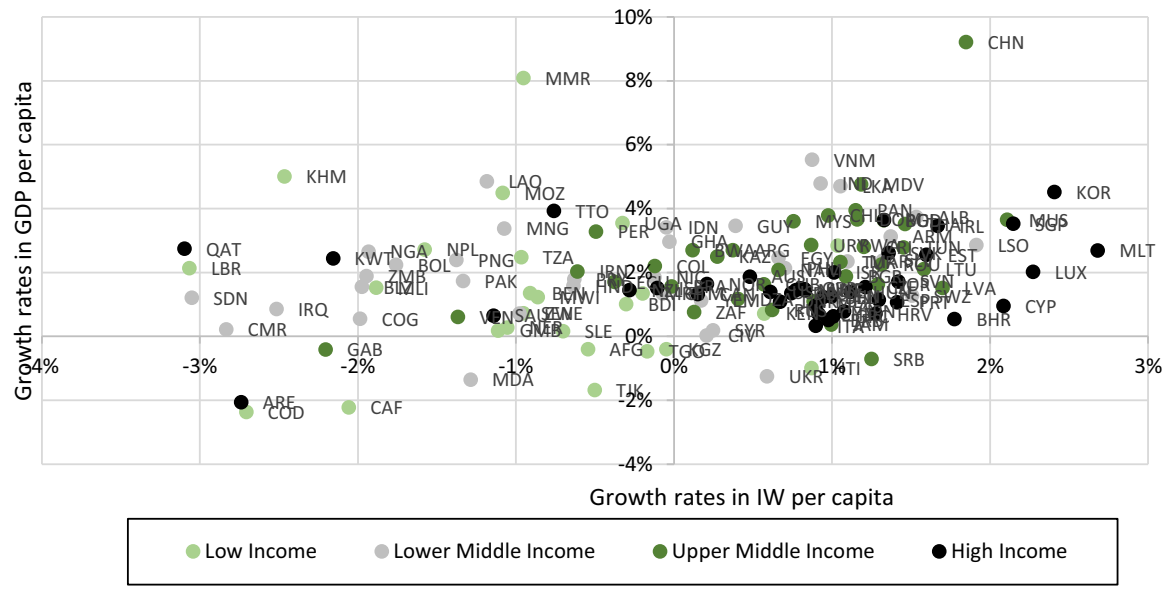

Fig. 5 Growth rates in IW per capita versus GDP per capita

the growth in IW does not resemble any of the plethora of other development indices with varied purposes, including GDP, HDI, happiness or even GS.

Finally, the publication of IWR 2018 almost coincided with the latest report on the Changing Wealth of Nations 2018 (CWN 2018) by the World Bank (Lange et al. 2018). As summarized in Table A.8 of the online supplement, it is safe to say that the two reports converge in terms of methodology. First, produced capital is recorded by a perpetual inventory method either by constructing data through investment and depreciation or by directly using other sources. Timber, non-timber forest benefits, and agricultural land compose renewable natural capital. However, notable differences remain, including the inclusion of urban land in produced capital $(\mathrm{CWN})$, fishery resources in natural capital (IWR), protected land in natural capital (CWN), net foreign assets (CWN), and the three adjustment terms (IWR). Human capital accounting in CWN is based on household surveys, but the two reports have in common the basic mechanism of the net present value of earnings as a forward-looking shadow price. Overall, our capital composition of IW in 2014 works out to be $24 \%, 64 \%$, and $11 \%$ for produced, human, and natural capital, respectively (Fig. 3c). This is almost in line with the result of CWN $(27 \%, 64 \%$, and $9 \%)$, where the inclusion of urban land and exclusion of fishery may explain the difference. A detailed investigation of how and why IWR and CWN differ in terms of empirical estimates should be performed in the future.

It is also important to place IW in an extended context of capital and income, which dates at least as far back as Fisher (1906). Ignoring capital gains, properly calculated national income is return on IW. As a rule of thumb, conventional wealth has been considered as several times the size of income, but this ratio has increased to $10-15$ or even more in high-income countries due to an increase in financial assets (Piketty 2014). It is interesting to see the order of the magnitude when we expand the definition of wealth to include human and natural capital. Here, the wealth/income ratio is defined as IW divided by GDP, $\beta=\frac{W}{Y}$, which works out to be 12.3 for the 
whole country sample in 2014. For robustness, we also check the wealth/income ratio in 2014 using World Bank's total wealth (Lange et al. 2018) and adjusted net national income (constant 2010 US\$, gross national income (GNI) minus consumption of fixed capital and natural resources depletion) as well as GNI (current US\$) (World Bank 2019). On average, the wealth/ANNI ratio and the wealth/GNI ratio work out to be 21.0 and 15.8, respectively (see Figure SIII in the Supplementary Materials).

Given that Piketty's definition of wealth comprises produced capital and financial assets in high-income countries and wealth here instead includes human and natural capital in all countries, these figures cannot be directly compared. However, we can safely state that human and natural capital are at least as important as financial assets. In addition, the rates of return on wealth are $4.8 \%$ for ANNI on total wealth of CWN, $6.3 \%$ for GNI on total wealth of CWN, and $8.1 \%$ for GDP on IW of IWR. However, even if they exceed the growth rates of income (ANNI, GNI and GDP), Piketty's concern about inequality does not necessarily apply. To see this, recall that Piketty's definition of capital comprises produced capital and financial assets, which he assumes mainly belong to capital owners, whereas human and natural capital income is largely attributed to a broader base of citizens in general. On the other hand, as pointed out by Barbier (2018), both human capital accumulation biased toward high-skill jobs and natural capital depreciation in low-income countries show some worrisome symptoms toward greater inequality in IW.

\section{Conclusion}

We find that almost 58-60\% of our sample countries have experienced growth in IW in the last quarter century. That does not seem to be a bad figure with which to start the twenty-first century, but on the flip side, some $40 \%$ of countries have seen insufficient wealth accumulation. It is most likely that natural capital has been used to increase produced and human capital almost equally; furthermore, there is no guarantee that this trend will continue. National policy makers should keep track of not only IW per capita but also specific classes of capital assets. They are also advised to perform social cost-benefit analysis using components of IWI (UNU-IHDP and UNEP 2014; Collins et al. 2017).

We have expanded our natural capital database in the latest IWR, but many relevant assets have been left out, such as biodiversity, pollution, water (UNU-IHDP and UNEP 2012; Fenichel et al. 2016a), and many aspects of human capital, including parenting, early childhood education, and on-the-job training, among others. In addition, the resilience of nature can be added as another essential capital to economies, at least conceptually (Mäler and Li 2010) and locally in practice (Walker et al. 2010). Moreover, shadow prices of capital assets are likely to change in the long run as their relative scarcity changes, particularly in the face of looming climate change (Fenichel et al. 2016b). They can also be addressed in IW accounting in the future.

Acknowledgements We acknowledge the advice and guidance of Partha Dasgupta, Barbara Fraumeni, Zakri Abdul Hamid, Anantha Duraiappah and Harold Mooney as science advisers to Inclusive Wealth Report 2018. For comments to Chapter 1 of the Report, we would also like to thank Eli Fenichel. We are 
also grateful to two anonymous referees, who provided rigorous and excellent comments. We acknowledge excellent contribution of Yogi Sugiawan, Robi Kurniawan and Isma Addi Bin Jumbri for preparing the data. We also acknowledge the financial support of United Nations Environment Programme (UNEP) and the technical support of Urban Institute, Kyushu University.

Author's contribution MI and RY performed the analysis; RY and MI wrote the paper; RY, MI and SM contributed to editing the paper.

Funding This research is supported by the following Grant in Aid from the Ministry of Education, Culture, Sports, Science and Technology in Japan (MEXT): Grant in Aid for Specially Promoted Research JP26000001. Any opinions, findings, and conclusions expressed in this material are those of the authors and do not necessarily reflect the views of the MEXT.

Open Access This article is distributed under the terms of the Creative Commons Attribution 4.0 International License (http://creativecommons.org/licenses/by/4.0/), which permits unrestricted use, distribution, and reproduction in any medium, provided you give appropriate credit to the original author(s) and the source, provide a link to the Creative Commons license, and indicate if changes were made.

\section{References}

Arrow, K.J., Dasgupta, P., Goulder, L.H., Mumford, K.J., Oleson, K.: Sustainability and the measurement of wealth. Environ. Dev. Econ. 17, 317-353 (2012)

Atkinson, G., Agarwala, M., Muñoz, P.: Are national economies (virtually) sustainable? An empirical analysis of natural assets in international trade. In: UNU-IHDP and UNEP, pp. 87-117 (2012)

Barbier, E.: Reconciling inclusive wealth and Piketty: natural capital and wealth in the 21 st century. Inclusive Wealth Report 2018, 114-135 (2018)

Collins, R.D., Selin, N.E., De Weck, O.L., Clark, W.C.: Using inclusive wealth for policy evaluation: application to electricity infrastructure planning in oil-exporting countries. Ecol. Econ. 133, 23-34 (2017)

Dasgupta, P.: Human Well-Being and the Natural Environment. Oxford University Press, New York (2001)

Dasgupta, P., Mäler, K.-G.: Net national product, wealth, and social well-being. Environ. Dev. Econ. 5, 69-93 (2000)

Fenichel, E.P., Abbott, J.K., Bayham, J., Boone, W., Haacker, E.M.K., Pfeiffer, L.: Measuring the value of groundwater and other forms of natural capital. Proc. Natl. Acad. Sci. 113, 2382-2387 (2016a)

Fenichel, E.P., Levin, S.A., McCay, B., Martin, K.S., Abbott, J.K., Pinsky, M.L.: Wealth reallocation and sustainability under climate change. Nat. Clim. Chang. 6, 237 (2016b)

Fisher, I.: The Nature of Capital and Income. McMillan, New York (1906)

Greasley, D., Hanley, N., Kunnas, J., McLaughlin, E., Oxley, L., Warde, P.: Testing genuine savings as a forward-looking indicator of future well-being over the (very) long-run. J. Environ. Econ. Manag. 67, 171-188 (2014)

Hamilton, K., Clemens, M.: Genuine savings rates in developing countries. World Bank Econ. Rev. 13, 333-356 (1999)

Lange, G.-M., Wodon, Q., Carey, K. (eds.): The Changing Wealth of Nations 2018: Building a Sustainable Future. World Bank, Washington, DC (2018)

Mäler, K.-G., Li, C.-Z.: Measuring sustainability under regime shift uncertainty: a resilience pricing approach. Environ. Dev. Econ. 15, 707-719 (2010)

Managi, S., Kumar, P. (eds.): Inclusive Wealth Report 2018: Measuring Progress Toward Sustainability. Routledge, New York (2018)

Piketty, T.: Capital in the Twenty First Century. Belknap Press of Harvard University Press, Cambridge (2014)

Steffen, W., Richardson, K., Rockström, J., Cornell, S.E., Fetzer, I., Bennett, E.M., et al.: Planetary boundaries: guiding human development on a changing planet. Science 347(6223), 1259855 (2015)

Stiglitz, J., Sen, A., Fitoussi, J.-P.: The Measurement of Economic Performance and Social Progress Revisited: Reflections Overview. Commission on Measurement of Economic Performance and Social Progress, Paris (2009) 
UNU-IHDP and UNEP: Inclusive Wealth Report 2012: Measuring Progress Toward Sustainability. Cambridge University Press, New York (2012)

UNU-IHDP and UNEP: Inclusive Wealth Report 2014: Measuring Progress Toward Sustainability. Cambridge University Press, New York (2014)

Walker, B., Pearson, L., Harris, M., Maler, K.-G., Li, C.-Z., Biggs, R., Baynes, T.: Incorporating resilience in the assessment of inclusive wealth: an example from South East Australia. Environ. Resour. Econ. 45, 183-202 (2010)

Weitzman, M.L.: Sustainability and technical progress. Scand. J. Econ. 99(1), 1-13 (1997)

World Bank: The Changing Wealth of Nations: Measuring Sustainable Development in the New Millennium. World Bank, Washington, DC (2011)

World Commission on Environment and Development: Our Common Future. Oxford University Press, New York (1987)

Yamaguchi, R., Managi, S.: Backward- and forward-looking shadow prices in inclusive wealth accounting: an example of renewable energy capital. Ecol. Econ. 156, 337-349 (2019)

Yamaguchi, R., Sato, M., Ueta, K.: Measuring regional wealth and assessing sustainable development: an application to a disaster-torn region in Japan. Soc. Indic. Res. 129, 365-389 (2016)

Publisher's Note Springer Nature remains neutral with regard to jurisdictional claims in published maps and institutional affiliations

\section{Affiliations}

\section{Rintaro Yamaguchi ${ }^{1}\left[\right.$ (]) Moinul Islam ${ }^{2,3}\left([) \cdot\right.$ Shunsuke Managi ${ }^{2,3}$}

$\bowtie$ Shunsuke Managi managi.s@gmail.com

Rintaro Yamaguchi yamaguchi.rintaro.r41@kyoto-u.jp

Moinul Islam

moinul.eco@gmail.com

1 National Institute for Environmental Studies, 16-2 Onogawa, Tsukuba 305-8506, Japan

2 Urban Institute, Kyushu University, 744 Motooka, Nishi-ku, Fukuoka 819-0395, Japan

3 Departments of Urban and Environmental Engineering, Kyushu University, 744 Motooka, Nishi-ku, Fukuoka 819-0395, Japan 